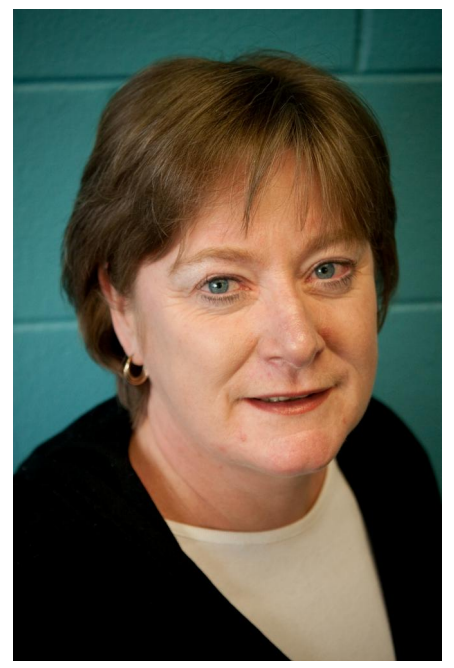

\title{
WHAT DO WE KNOW ABOUT NEW ZEALAND WORKPLACES?
}

\author{
Rose Ryan \\ Heathrose Research \\ Ray Markey \\ Auckland University of Technology
}

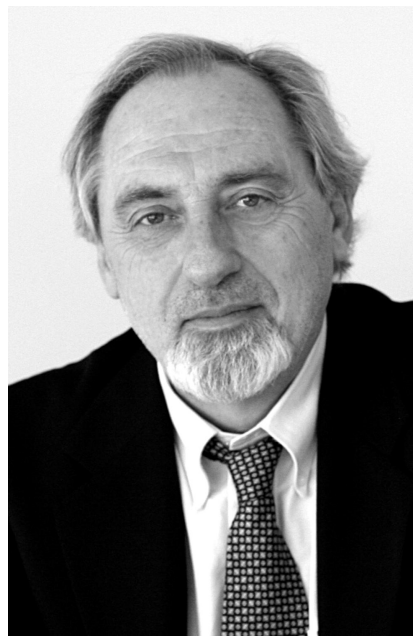

\begin{abstract}
Over recent years, as interest has grown at a national level in improving productivity and performance, the workplace has received increasing research attention as a unit of analysis. Internationally, the existence of a High Performance Work Systems model has been debated, and there has been an outpouring of articles giving consideration to the range of workplace practices that are associated with this model. This has been facilitated by the existence in many countries of large-scale surveys that provide a systematic and robust evidence base for informed policy making.

Within the New Zealand context, however, the empirical basis for drawing conclusions about the nature and spread of a range of workplace practices is sparse, and limited by the data available in official statistics and a continued reliance by researchers on small-scale case studies. This paper considers the limits of our knowledge about the dynamics of New Zealand workplaces, and questions whether the time has come for development of a large scale survey to provide robust empirical evidence to better inform decision-making by policy makers and practitioners.
\end{abstract}

\section{Introduction}

Until the 1990s, industrial relations research in New Zealand was dominated by a focus on institutions, regulation and the activities of statutorily-created actors. This changed dramatically from the late 1980s, and more particularly in the wake of the passage of the Employment Contracts Act in 1991. For the first time in decades the key locus of industrial relations and bargaining activity occurred at the workplace between employers and employees directly, rather than in formal conciliation councils by industry employer advocates and union officials.

New Zealand was not alone in decentralising bargaining. In addition, changes in production systems as a result of new technology, increased competition as a result of industry de-regulation and the rise of Human Resource Management strategies to replace the earlier "personnel" function resulted in increased attention being paid to workplace dynamics. In light of this interest many countries have enlarged their research investment in consideration of workplace related issues. Workplacebased surveys (sometimes regular, sometimes ad hoc) to collect large-scale data have been put in place in the UK, Australia, Canada, France, Norway and Germany
(Delbridge and Whitfield 2007; Bryson and Frege 2010). This information has provided a solid evidence base for informing policy making on a range of social and economic policy decisions. In contrast, the information available on New Zealand workplaces is relatively thin.

The authors of this paper, together with representatives from four Universities, the Department of Labour, and the Employment Relations Society have, for the last year, been involved in a project to map the current state of knowledge in New Zealand about how workplaces operate, what employment, industrial relations and human resources practices are utilised at workplaces, and the impact of these practices if any, on innovation and labour productivity at workplaces. While work is ongoing, our view is that there are substantial gaps in our knowledge about the dynamics of workplace operation, and how different dynamics impact on workplace innovations and productivity. We argue for the development of a new large-scale survey that would provide a new data set to throw light on these issues.

\section{Background}

The past three decades have seen massive changes in the structure and nature of economies across the developed 
and developing worlds. A conglomeration of factors including new technologies, de-regulation, globalisation, increased competition and changing patterns of trade have all resulted in a situation where firms have had to adapt their business strategies and models to be successful in the new environment.

Over the same time period, research has turned to the question of why some organisations have been better able to develop and implement these adaptive strategies than others. The search for answers has considered the place of new technology, investment and research and development, management capability, skills and training and a range of other factors. While all undoubtedly have an important role to play, no single factor has been able to convincingly explain why some workplaces perform better than others. More recently, attention has been paid to what happens within the "black box" as it has become commonly referred to (Ramsay et al 2000; Chartered Institute of Personnel and Development 2003) - referring to the internal workings of firms and workplaces.

The metaphor of the black box is particularly apt for considering the operations of workplaces from a systems point of view. In science and engineering, the internal workings of the black box are opaque, and are seen solely in terms of inputs and outputs. From a theoretical perspective we cannot "look inside" the black box to see how it works, but can only make an educated guess about the process of transformation that is occurring. The same is true of workplaces - while inputs and outputs can be measured, they do not necessarily explain the complex dynamics occurring that would otherwise explain why firms delivering the same services or producing the same products, using the same technology, in the same or similar markets, using the same or similar types of labour input should exhibit such different results.

These factors have led to the development of workplace surveys in several countries. Their common features include a focus on the workplace as the unit of analysis, comparable sampling techniques (stratified random samples), coverage across all industries and sizes of workplace and similar content (workplace practices). However, perhaps their most significant feature is the collection of data from a range of respondents at the same workplace (employees as well as managers), in order to explore multiple perspectives on workplace operations and to consider how workplace relationships themselves impact on workplace productivity and performance.

Unlike other countries, New Zealand has no systematic and comprehensive survey for the collection of workplace-based data, despite debate in the mid-1990s about the desirability of so doing (Ryan 1996; Boxall 1997). Consequently little is known about a range of workplace practices that have both immediate and future policy relevance. The restricted data that is available comes from a limited number of questions on a small number of issues contained in official statistics, small scale and "one-off" surveys undertaken around specific policy issues (e.g. recent research evaluating the impact of the trial employment periods, rest and meal breaks and infant feeding amendments to the Employment Relations Act), and research case studies based usually around individual industries and specific issues.

There are limitations in all these sources of information. Labour-related information is collected by Statistics New Zealand at both the workplace level (including the Annual Enterprise Survey, Quarterly Employment Survey and Business Operations Survey) and at the household and individual level (specifically the Household Labour Force Survey, including the supplements that are put in the field from time to time). While the data clearly meets the statistical gold standard of being based on robust sampling techniques and generalisable to the whole population, the scope of the questions asked tends to be limited and the form of the questions asked is often fairly general and high level.

As noted above, Department of Labour research (quite understandably) tends to be centred on very specific and short-term policy issues and is frequently evaluative in nature. Research undertaken by academics and private researchers leans heavily towards case studies using qualitative methodologies, small-scale surveys using sampling frames that are not particularly robust, and research on specific issues in specific sectors. These limitations are noted not to be critical of individual pieces of research (carried out by a small research community under significant resource constraints and with often unrealistic expectations by funders about what can be achieved within time and budget constraints) but to underscore the point that there is no comprehensive source of information about workplace operations that is robust and generalisable, despite the significant research investment that is currently being made across a range of funders.

We are interested to explore the development of a single database that could provide robust information that could be interrogated to answer a range of different policy questions across a range of industries and sizes of workplaces. As a start to this process, a map of current research in the area was undertaken in 2010.

\section{Looking into the Black Box: What do we know about workplace practices in New Zealand?}

Seven broad areas of workplace operation are of interest for both policy reasons and because of their continued importance for adjustment to future economic and social conditions. The rest of this section outlines these areas, identifying what we currently know (through existing data or research) $)^{1}$ and what other policy-relevant questions we lack information for. In addition, two other areas of data collection (workplace performance indicators and the collection of workplace and employee demographic data) have been identified as being critical for being able to answer research questions about the impact of labour-management practices on both workplace performance and social inclusion. 


\section{Employment Relations/Human Resources Management Practices}

Fundamental to an improved understanding of the relationship between labour-management practices and workplace performance indicators is the range of practices that are implemented at workplaces to manage employees on an individual and collective basis.

The information available in New Zealand on these issues is patchy. What we do know comes largely from the database of collective agreements maintained at VUW's Industrial Relations Centre. This is collected on a regular basis and distributed widely in an annual Employment Agreements: Bargaining Trends and Employment Law Update book. ${ }^{2}$ This provides general information on wages and conditions of work in workplaces with formal collective agreements, negotiated with a registered trade union. In addition, the Department of Labour has recently concluded research on the effect of the Employment Relations Act on collective bargaining, looking particularly at the impact of the Act on unionisation, the type and content of collective agreements, and the costs and benefits of collective bargaining for employers and employees (Department of Labour 2009).

There are, however, significant gaps in current knowledge, the biggest of which is that information is collected on collective but not individual agreements. Given that (according to the recent Survey of Working Life) only a quarter of employees are employed under collective agreements and that collectives are more likely to be in place in large workplaces, this leaves us with virtually no understanding of the wages and conditions of the majority of employees and in the majority of workplaces.

A second gap is that collective agreements only include a small proportion of the policies and practices that constitute the way in which the employment relationship is constructed at the workplace. Little is known about a range of human resource practices (with the exception of Edgar's 2003 study of human resources management practises in 40 workplaces) including processes for recruitment and selection of staff, work allocation, rewards policies and who is responsible for $\mathrm{HR}$ at the workplace.

The one exception to this is in relation to performance management, reflecting the interest in this topic in both New Zealand and internationally. In this area, the evidence consistently suggests that New Zealand workplaces lag behind their international counterparts. The latest Business Operations Survey demonstrated that around a third of workplaces have no formal performance reviews for any employees, and only $37 \%$ had them in place for more than $50 \%$ of employees. In addition, a recent survey of 152 medium and large-sized manufacturing firms (MED 2010) found that against six indicators of people management (installing a talent mind-set, rewarding top performance, addressing poor performance, promoting high performers, attracting high performers, retaining high performers) New Zealand performs relatively poorly, ranking 14 th out of 16 countries.

This lack of quite basic information suggests that understanding how the incidence and scope of human resource management practices and processes affects workplace performance is undervalued in New Zealand. Certainly when it comes to self-assessment, organisations are more likely to place priority on financial measures (66\% placing a great deal of focus on this) and cost measures $(53 \%)$ over quality $(41 \%)$ operations $(34 \%)$ innovation $(15 \%)$ or HR $(23 \%)$ (Business Operations Survey 2009).

\section{Employee engagement and representation}

Internationally, information on the number and size of trade unions is collected and published as a standard indicator of labour market outcomes. In New Zealand an annual survey undertaken by the Industrial Relations Centre at Victoria University provides information on numbers of unions, membership, industry, gender and affiliations to central trade union bodies. Although the Employment Relations Act requires that registered unions must deliver an annual membership return to the Registrar of Unions this information is not made publicly available. The only other information on union membership is a new question in the Survey of Working Life that suggests that around $30 \%$ of employees are union members.

There are a number of gaps in our knowledge about employee representation at the workplace. For example, we know there has been a growth in the number of unionmanagement consultative committees negotiated into collective agreements and that those agreements covered $40 \%$ of employees in 2008 (Lafferty 2008). We know little, however, about the operation of these committees what issues they discuss, how frequently they meet, how effective they are and the impact they have on workplace operation and relationships. Neither do we have any knowledge of whether workplaces that do not engage in collective bargaining have non-union structures in place for employee representation, and whether or not these differ materially (in structure or in the scope of issues discussed) from those provided by registered unions.

The engagement of employees, both individually and collectively, is argued to make a significant difference to the commitment of employees to the workplaces in which they work and the discretionary effort that they apply in their work. This is likely to have consequences for innovation and productivity at the workplace. A better understanding of the structure and processes in place at workplaces, and the impact of alternative options, will provide valuable information for future policy-makers.

\section{High Performance Workplace Practices}

The subject of "high performance" workplace practices has received considerable attention in recent years. Taken collectively, they are said to involve changed forms of work organisation, an increased focus on training and 
skill development, mechanisms for two-way communications and improved human resource management (HRM) processes. Important questions that have been addressed include workplace characteristics associated with the high performance model, and barriers to the adoption of different practices. An important debate has been around the question of whether in fact they deliver more positive outcomes for workers or, alternatively, whether they result in work intensification and work-related stress. Western governments have had a particular interest in initiatives to increase the uptake of these practices, as part of the arsenal of policy interventions for improving productivity.

Research into workplace practices in New Zealand has been relatively limited. During the course of the 1990s, a handful of case studies on innovative work practices were carried out in New Zealand workplaces (Ryan 1993; Perry et al 1995). However, the overall incidence of such practices across industry in New Zealand is unknown, with the exception of the latest Business Practices module in Business Operations Survey (BOS). ${ }^{3}$ Using earlier BOS data, questions about the use of "bundles" of practices have been addressed by Fabling and Grimes (2009) who conclude that, as has been found in other countries, "suites" of practices have a strong effect on firm performance in terms of raising productivity, better staff retention and higher average human capital in workers.

A number of other gaps in our knowledge exist. One of the questions that emerged in the 1990s was the sustainability of such practices over time, and whether their adoption is part of a long-term change in the nature of production. The amount of research that has been carried out in other countries on high performance practices offers New Zealand the chance to debate whether the take-up of such practices is as high as it might be, or alternatively whether there are unique features of our situation (such as the structure of industry, workplace size or geography) which make this less relevant.

A further gap is in understanding the experience of employees in workplaces that have adopted a high performance model. Rasmussen (1996) has suggested the adoption of "best practice" models is limited and does not in fact promote high productivity or morale. On the other hand, Macky and Boxall (2008) have argued that New Zealand workers are relatively empowered by high performance workplace practices (HPWP). Additional research is needed to understand the operation of these practices at workplaces, in particular in the light of the clear international evidence of their impact on workplace productivity and performance.

\section{Skill development and utilisation}

Training and skill formation is an area of high priority for policy attention internationally. This reflects the identified importance of skills for competitive advantage of industries and economies, changes occurring in the structure and nature of work and the emergence of the "knowledge economy". Skill development is also crucial from a social development perspective with educational qualifications and skills levels of crucial importance in explaining labour market disparities between individuals and groups (Dixon, 1998).

Unlike some other areas, the recognised importance of skill development has resulted in considerable research activity over the past two decades. The Education and Training Supplement to the Household Labour Force survey in 1996 was the first of these to comprehensively map the participation of wage and salary earners in training, finding not surprisingly that more $(23.2 \%)$ participated in in-house than external (13.5\%) training (Gobbi 1998). Most recently, the Survey of Working Life has found that $30.9 \%$ of employees had undertaken some employer-funded study or training over the previous 12 months, with about half of these spending two to five days in training.

Data has also been collected at the workplace. Regular surveys of training activity have been undertaken by employer organisations since 1989, with the most recent being 2003 (Business NZ/Industry Training Federation 2003). The BOS also includes a range of questions on training, which has been subject to comprehensive analysis by Barnes and Dixon (2010). Case studies at industry level ${ }^{4}$ have been undertaken as part of the Developing Human Capability project at Victoria University. These have resulted in new insights on the institutional and organisational influences on the development of human capability in New Zealand organisations (Bryson 2010).

Despite this, gaps in our knowledge remain. They include issues related to skill mismatches, how to promote the acquisition of skill for those members of the labour force with low or no educational qualifications and why some workplaces continue to exhibit a low level of commitment to training. By far the most significant of these issues however, comes from contemporary research questions about the utilisation of skill at workplaces and the relationship between utilisation and workplace performance.

\section{Flexible working arrangements and work-life balance}

An important aspect of job quality is the extent to which it allows employees and families to maintain an adequate balance between the time spent in work and other activities. This area has received increasing research attention internationally over recent years, as new technology has increasingly blurred the boundary between working time and private time. Added to this has been a change in working patterns away from the traditional 40-hour, five-day week in favour of nonstandard working patterns occurring in response to change in preferences by both employers and employees.

The twin issues of flexible working and work-life balance have been relatively well researched in New Zealand over recent years as a result of policy and academic interest 
(see in particular Fursman 2006; Callister 2007; Haar and Roche 2008; Haar, Spell and O'Driscoll 2009) and the collection of official statistics in this area for the first time in the Survey of Working Life. Overall, these studies suggest employees are reasonably satisfied with their work-life balance, but that it is difficult to achieve at times. Additionally, the Survey of Working Life has found $48 \%$ of employed people have flexible hours of work and about $90 \%$ believed their employer would let them take a few days of unpaid leave if they needed to.

The existing research does, however, suggest that not all employee groups are equally able to access arrangements that suit them, or that workplaces are equally able to manage flexible working arrangements. Most of the flexibility required by employees is relatively low-level, including the ability to have flexible start and finish times, being able to leave in an emergency, using sick or domestic leave. While employers report commonly offering these, it is evident they are more likely to be offered to senior or management staff.

Paid parental leave (PPL) is an additional area of policy interest both in New Zealand and internationally. Callister's (2007) evaluation of PPL legislation found a high level of support amongst parents and employers. However, workplace dynamics have an impact on the uptake of leave amongst mothers as a result of variables such as awareness of policies, ethical obligations to the employer, perceived flexibility in working patterns and the type of role they have in the workplace. Similarly, fathers reportedly found employers supportive of changed work patterns at the time of a child's birth, but not over the longer term.

It is clear from existing studies that managing parental leave can be problematic for employers. Most employers have little experience of managing it - although the exact incidence is not known. Questions remain about this, and also about the ways in which employers manage during a period of PPL (e.g. employing a temporary replacement or redeploying existing staff). In addition, some interesting issues exist around determining whether employers have a greater readiness to accommodate changes in working patterns on a long-term basis for mothers than for fathers.

\section{Job quality, job satisfaction and employee well- being}

There is growing interest in the topic of job quality, spurred in part by the adoption of the ILO's Decent Work agenda. The work of the Good Work Commission in the $\mathrm{UK}$ is also evidence of a growing interest in the subject of job quality.

Interest in these subjects emerged from the rapid growth in non-standard working patterns in the 1990s. While it was recognised that non-standard work appealed to some, concerns about the wages and working conditions of these employees were expressed. New Zealand has only recently collected information on the incidence of nonstandard work, through both the BOS and the Survey of
Working Life. This tells us that, while working at nonstandard times is relatively common for the majority of employees, this is largely a function of working long hours. Non-standard employment arrangements are less common with only $9.4 \%$ being temporary employees (casuals, fixed-term contracts and agency workers).

Issues of job quality and employee well-being are significantly under-researched in New Zealand. The Survey of Working Life will assist in filling some of this gap, collecting data on job tenure, work stress and job satisfaction. Initial results are however somewhat puzzling - $84.1 \%$ reported being satisfied or very satisfied with their main job, but nearly $60 \%$ found work sometimes or always stressful in the previous 12 months. In addition, $13.9 \%$ reported often or always being too tired to enjoy life outside of work, $9.8 \%$ had experienced discrimination, harassment or bullying. More research is needed to unpick job and workplace-related factors associated with job satisfaction and employee well-being, and how these contribute to workplace performance.

Two specific areas are of particular policy interest. The first of these is how our relatively short level of job tenure on an international basis $(23 \%$ of people have been in their jobs for one to three years and only $40.6 \%$ have been in their jobs for five years or more) impacts at the workplace. Of interest too is the question of why people change jobs, and whether this is as a result of push or pull factors. The relative importance of employment security, and how management practices contribute to this are also important in relation to current policy interest in trial employment periods.

A second issue, which has received little attention in New Zealand, is the relationship between the workplace and personal health. This extends beyond traditional health and safety concerns (which have been largely focussed on workplace hazards and accidents) and extends into how workplaces manage employees with personal health issues (particularly mental health issues), and the business benefits for workplaces of assisting employees to improve their personal health. These issues have received significant government attention in the United Kingdom, particularly with the prospect of a rapidly-aging workforce.

\section{Workplace climate}

The importance of collecting information on workplace climate rests on the assumption that a more positive workplace culture is associated with higher levels of productivity and performance. The international evidence to support these propositions is contentious, and there is almost no New Zealand evidence to contribute to the debate. However, a recent evaluation of business improvement projects in seven workplaces concluded that "soft" factors, including culture, communication, internal relationships and leadership and management style were the biggest determinants of success (Harvey and Harris 2009). 
An important part of the debate on workplace climate is the extent to which disputes occur at the workplace. While there is a long-standing statistical series on strikes and lockouts where these involve more than five or more person-days lost, we have much less information on disputes and grievances that are settled without recourse to industrial action. Evidence from the late 1990s (Colmar Brunton 1997) showed around a quarter of all workplaces have a dispute or grievance occur in the course of a year, and that most are resolved at the workplace, but little is known about the long and short-term costs of these at the workplace. The Department of Labour has recently undertaken a small-scale review of employment relationship problems, which suggested a somewhat lower rate than this (Woodhams 2007), but it is unclear as to why this might be the case ${ }^{5}$. In addition, this review largely identified further research questions, including the need to have a more in-depth understanding of the economic and qualitative impact of such problems.

Research on the origins, underlying causes and costs of grievances has a high degree of policy relevance. Any deterioration in workplace climate that results in an increase in the number of grievances adds costs for both the parties and for government (in terms of provision of resolution services). Identifying successful strategies for avoiding grievances, and resolving them at the lowest level possible, potentially leads to significant cost savings for the parties and the Government. Analysis of the way in which current procedures are understood and made use of by employers and employees would provide a better evidence base from which to make future policy decisions and anticipate their impact.

An additional gap in our understanding of workplace climate is related to the prevailing management style in New Zealand workplaces. At least one private mediator has argued that the causes of workplace conflict in New Zealand lie in hierarchical workplace structures, and a workplace climate based on exercise of managerial prerogative, individualism rather than team-work and suppression of conflict (Hooper 1997). That there is considerable room for improvement in people management practices is also supported by the recent New Zealand Management Practices and Productivity survey, which found that New Zealand management practice is fair to middling in comparison to other countries (MED 2010).

\section{A workplace performance survey in New Zealand?}

The gaps identified above suggest the need for additional research investment to collect information from employers and employers on variables associated with workplace innovation and productivity. The remainder of this paper makes the case for a large-scale national survey for New Zealand to gather this evidence. The arguments in favour of such a survey are the need for a reliable and comprehensive data set to establish the nature, extent and implications of changes in workplace practices across workplaces. By being large-scale it would ensure that it would be representative of the whole population of New Zealand workplaces, including public and private and not-for-profit sectors, across all industries, and workplaces of different sizes.

A comprehensive survey with a wide scope would allow not only new information to be gathered, but also the testing of relationships between different variables. This would provide valuable information on the quality of management practice and the way in which these impact on performance. However, the most significant feature of a workplace survey would be to allow information to be collected from both employers and employees, allowing for the first time in New Zealand for the possibility of testing the multiple ways in which the dynamics of workplace operations influence productivity and performance.

The proposed purpose of the survey would be:

- To map the performance of New Zealand workplaces in respect of productivity, innovation and inclusion

- To assess the labour-management practices that are associated with high performance in these areas

- To inform policy development and stimulate and inform debate

- To provide a comprehensive and statistically robust data set, which is publicly available and readily accessible

Underpinning these purposes lie a number of high level research questions. These include:

- What criteria do managers in New Zealand use to assess the performance of their workplaces?

○ How productive are New Zealand workplaces?

- What labour-management practices are in place in New Zealand workplaces?

- How do labour-management practices impact on productivity and performance?

- What workplace and employee variables are associated with the uptake of different labourmanagement practices?

It is important to ensure there is general agreement with the survey purpose and these high-level research questions. The experience of developing workplace surveys in a range of countries is that the range of issues on which stakeholders want information is so large as to increase the size and length of questionnaires to the point where it imposes a high respondent burden, or alternatively where the questions asked do not provide meaningful information. Getting the high level research questions right provides a criteria for weeding out data 
items that may be of interest, but do not contribute to the high level research objectives or cannot be operationalised in a meaningful way.

The detailed content areas of the proposed survey will also need to be the subject of discussion and consideration by stakeholders, including researchers. While it is clear there are some key areas of policy concern, it is important that content strikes a balance between collecting data on issues of current short-term interest and those issues which will assist in making longer term decisions, particularly around issues which will facilitate improved workplace performance and social inclusion

In order to be able to meet the objectives of the survey, information would be sought on a range of workplace performance indicators. Currently the core Business Operations Module of the annual BOS includes questions on a range of indicators related to performance, including percentage of sales from exports, research and development activity, and international presence. Some questions ask directly about profitability and productivity, but they are self-report measures based on comparison with competitors, and whether the indicators have increased, decreased or stayed the same over the previous year. As Fabling, Grimes and Stevens (2008) point out, the psychological literature points to the hazards of relying on self-reports, although they do find that there is in fact a reasonable degree of commonality between the BOS self-reports and administrative data collected by IRD on financial accounts. An alternative approach is taken in the UK WERS, where subjective analyses of workplace productivity and financial performance were replaced in 2004 with a financial performance questionnaire which allows calculations to be made of average labour productivity (based on dividing total employment at the workplace into the total value of sales) and value-added per worker (operating costs divided by total employment).

In addition to workplace performance indicators, the proposed survey could usefully include basic demographic information about both the workplace and the employees employed within it, to allow analysis of the incidence of labour-management practices in different types of workplaces and their impact on different types of workers. It would, for example, illustrate more specifically the ways in which employment relations practices vary between large and small workplaces, and would help to inform policy debates on the extent to which employment regulation constrains the operation of small business. Similarly, such data could help to illuminate the extent to which labour-management practices vary between the public and private sector, or by industry grouping.

Collection of demographic data about the employees employed in a workplace would add vastly to our understanding of the employment experiences of different groups of New Zealand workers. The 2008 Survey of Working Life, undertaken as a supplement to the Household Labour Force Survey, demonstrates the value of this information by providing information about some aspects of the work experience (e.g. non-standard working arrangements, ability to work from home, job satisfaction, stress at work) and how these vary by individual characteristics such as age, ethnicity and occupation. These analyses have not yet, however, been undertaken. In addition, we have no understanding of the labour-management practices used in the workplaces in which they work, or of the extent to which these are experienced positively or negatively in their work environment. This would aid in a deeper understanding of whether work experiences are similar or different for different groups of New Zealanders, and to inform wider debates about social inclusion.

\section{Conclusion}

The paper has considered the arguments in favour of further research related to workplace performance and innovation in New Zealand, in light of the policy relevance of these issues for economic development and social inclusion in New Zealand. We note that in contrast to the breadth and depth of information available in other countries, New Zealand evidence is relatively thin. In order to make most efficient and effective use of available research resources, we argue that there is a case for a workplace survey which establishes a data base that is able to answer a wider range of research questions from a robust and generalisable evidence base.

\section{Notes}

1. In looking at current relevant information, the focus has been on data and research reports that have been completed in the years 2000 - 2010. These were sourced through:

- searches through the websites of the Department of Labour, the Ministry of Economic Development and the Department of Statistics;

- contents pages from conference proceedings from the Biennial Labour Employment and Work Conference and the annual Association of Industrial Relations Academics of Australia and New Zealand conference;

- contents page from the NZ Journal of Industrial/Employment Relations, the NZ Journal of Human Resource Management, the Asia-Pacific Journal of Human Resource Management, and the now-defunct Labour Market Bulletin

○ web pages of known researchers in the area, mostly in Business Management and Human Resources Schools at Auckland, Massey, AUT, Waikato, Victoria and Otago Universities.

2. In addition, all collective agreements are required to be sent to the Department of Labour when they have been negotiated, for statistical and analytical purposes. The Department has not, however, published any information from them or made this data widely available. 
3. Data collected as part of the 2009 module show that $65 \%$ of workplaces report they always or frequently incorporate the requirements of employees in planning goals for the business, and $45 \%$ promote company values to employees a great deal $(35 \%$ a moderate amount). High proportions of workplaces (between 67 and 83\%) also report communication of organisational goals, business plans, and major changes. Other questions look at issues, for example, employee autonomy to contact external suppliers.

4. These included industry case studies of mental health services, Mäori book publishing, wine making and furniture making.

5. Note that the research report does not include detail on the numbers of employers responding to the survey that was undertaken for this review, but does note that a response rate of only $11.5 \%$ was achieved.

6. The relevant variables included the extent to which businesses include the requirements of employees in developing goals, the extent to which the businesses promoted its values to employees, whether nonmanagerial employees have the authority to contact external suppliers, the focus placed on human resources in assessing business performance, whether employees have formal performance reviews and are paid on the basis of their performance, training of staff and whether non-managerial staff are actively encouraged to suggests improvements.

7. The definition of economic significance used by Statistics New Zealand is based on having a GST turnover of $\$ 30,000$ or more p.a. and at least one employee.

\section{References}

Barnes, M. and Dixon, S. (2010) Employer-funded education and training: who receives it? Wellington: Department of Labour.

Boxall, P. (1997) Models and Employment and Labour Productivity in New Zealand: An interpretation of change since the Employment Contracts Act. New Zealand Journal of Industrial Relations 22(1):2236.

Business NZ/Industry Training Federation (2003) Report of the Business NZ Skills and Training Survey 2003 (unpublished).

Bryson, A. and Frege, C. (2010) The importance of Comparative Workplace Employment Relations Studies. British Journal of Industrial Relations 48(2):231-234.

Bryson, J. (ed.) (2010) Beyond Skill: Institutions, Organisations and Human Capability, Palgrave MacMillan.

Callister, P. (2007) Parental Leave in New Zealand 2005/2006 Evaluation. Wellington: Department of Labour.
Colmar Brunton (1997) Survey of Labour Market Adjustment Under the Employment Contracts Act 1991. Prepared for Department of Labour, Industrial Relations Service.

Cully, M., Woodland, S., O'Reilly, A. and Dix, G. (1999) Britain at Work: As depicted by the 1998 Workplace Employee Relations Survey. Routledge: London and New York

Chartered Institute of Personnel and Development (2003) Understanding the People and Performance Link: Unlocking the Black Box. London: Chartered Institute of Personnel and Development.

Delbridge, R. and Whitfield, K. (2007) More than mere fragments? The use of the Workplace Employment Relations Survey data in HRM research. International Journal of Human Resource Management 18(12): 2166-2181.

Department of Labour (2009) The Effect of the Employment Relations Act 2000 on Collective Bargaining. Wellington: Department of Labour.

Dixon, S. (1998) Growth in the Dispersion of Earnings 1984-97. Labour Market Bulletin, 1998 1\&2

Edgar, F. (2003) Employee Centred Human Resource Management Practices. New Zealand Journal of Industrial Relations 28(1):13-22.

Fabling, R., Grimes, A., and Stevens, P. (2008) A Comparison of Qualitative and Quantitative Firm Performance Measures. Ministry of Economic Development Occasional Paper 08/04

Fabling, R. and Grimes, A. (2009) The "suite" smell of success: complementary personnel practices and firm performance. New Zealand Reserve Bank Discussion Paper Series, December 2009

Fursman, L. (2006) Work-Life Balance in New Zealand: A Snapshot of Employee and Employer Attitudes and Experiences. Wellington: Department of Labour.

Gobbi, M. (1998). Participation in post-compulsory education and training in New Zealand. Labour Market Bulletin, Issue 1\&2, pp.108-126.

Haar, J. M. \& Roche, M. (2008). Employee Perceptions of Organisational Support for Work-Family Issues and Outcomes: The Moderating Effects of Supervisor Support. New Zealand Journal of Human Resources Management, 8:1-27.

Haar, J., Spell, C. \& O'Driscoll, M. (2009). Managing work-family conflict: Individual and organizational options. New Zealand Journal of Human Resource Management, 9(3), 200-215.

Harris, P., Harvey, O., and Huddart, A. (2005) Being More Like Ourselves: Smart New Zealand 
Enterprises. Wellington: Growth and Innovation Advisory Board.

Harvey, O. and Harris, P. (2009) Workplace Productivity Projects: Evaluation Report. Unpublished, Department of Labour.

Hooper, S. (1997) The Use of Private Mediation in Organisational Disputes and Personal Grievances: the Experience of the Waikato Mediation Service. Proceedings from the $7^{\text {th }}$ Labour Employment and Work Conference, Victoria University of Wellington.

Lafferty, G. (2008) The Employment Relations Act and Collective Bargaining Patterns: A Review of the 2007/2008 year. In Lafferty, G. and Kiely, P. Employment Agreements: Bargaining Trends and Employment Law Update 2007/2008. Wellington: Industrial Relations Centre.

Macky, K. and Boxall, P. (2008) Employee Well-being and Union Membership. New Zealand Journal of Employment Relations 34(3):14-26

Ministry of Economic Development (2010) Management Matters in New Zealand - How does manufacturing measure up? Findings from the New Zealand Management Practices and Productivity Global Benchmarking Project. Wellington: Ministry of Economic Development.

Morehead, A., Steele, M., Alexander, M. Stephen, K., and Duffin, L. (1997) Changes At Work: The 1995 Australian Workplace Industrial Relations Survey. Melbourne: Department of Workplace Relations and Small Business.

Perry, M., Davidson, C. and Hill, R. (1995) Reform at Work: Workplace Change and the New Industrial Order. Auckland: Longman Paul.

Ramsay, H., Scholarios, D. and Harley, B. (2002) Employees and High-Performance Work Systems: testing inside the Black Box. British Journal of Industrial Relations 38(4):501-531.

Rasmussen, E. (1996) Employee awareness and attitudes - a pilot survey. Labour Market Bulletin 1996: 2 pp $89-101$.

Ryan, R. (1993) Japanisation or a New Zealand way?: five years on at Nissan New Zealand. Wellington: Industrial Relations Centre Working Papers Series 5/93.

Ryan, R. (1996) Should New Zealand have a WIRS? Labour Market Bulletin 1996: 1 pp101-111.

Woodhams, B. (2007) Employment Relationship Problems: Costs, Benefits and Choices. Wellington: Department of Labour. 